\title{
Water fluoridation - controversy or not?
}

\section{Derek Richards}

\section{Editor}

\section{Controversy - a prolonged argument or dispute, especially when conducted publicly [Oxford English Dictionary]}

In this issue we take a detailed look at the systematic review of water fluoridation published by the Centre for Reviews and Dissemination, ${ }^{1}$ a summary of which appeared in the British Medical Journal with additional material available on their website. ${ }^{2}$

Evidence-Based Dentistry (2002) 3, 31. doi:10.1038/sj.ebd.6400120

The story of introduction of water fluoridation is now more than a century old and artificial adjustment of the level of fluoride in drinking water has been conducted for more than 50 years. Nevertheless, the long-standing argument over whether it is of benefit or harm to humans still rages on. To my mind and according to the Oxford English Dictionary, this means that water fluoridation is a controversy: it is certainly a prolonged argument that has been conducted in the public arena.

What I believe the review shows is that there is evidence related to water fluoridation but the quality is not as high as we believed. This finding is similar in many other topics in dentistry where systematic reviews have been conducted. The rigour of the review also means that the conclusions are more cautious than those in previous reviews. There is evidence to support that fact that fluoride reduces tooth decay, but not by as much as previously thought. The review confirms the link between fluoride and fluorosis which, after all, is what started Frederick McKay off in search of the cause of 'Colorado Stain' in the early part of the last century. Despite suggested links with a wide range of other negative effects, such as bone fractures and cancer, no evidence was found to support a link. The quality of evidence, however, was too poor to establish this with confidence.

The York review team and its advisory panel produced a balanced systematic view of the research evidence available. Both pro- and anti-fluoridation groups have then used the review in equal measure to support their arguments. In both cases there has been much hyperbole. Those of you who areinterested may like to look at how the results of the review have been interpreted on the following websites from each side of the argument:

- British Fluoridation Society, at http://www.liv.ac.uk/bfs/

- National Centre for Fluoridation Policy and Research, at http://fluoride.oralhealth.org/

and two anti-fluoridation sites:

- http://www.fluoridation.com/ and

- http://www.holisticmed.com/fluoride/
The fact that both sides of the argument have criticised the review in about equal measure emphasises to me that the review is balanced. I must declare an interest, however, as a member of the Advisory Panel.

Clearly the review does not provide clear answers to all the questions related to fluoridation, but it did highlight a number of potential issues in relation to future research. Currently we await the outcome of a Medical Research Council review of what future research should be conducted in the area of water fluoridation. Although there is a clear need for more and better quality research, I doubt whether the zealots on either side of the argument will ever be satisfied: it is difficult to prove a negative. I leave you with a thought from Oscar Wilde and hope that you enjoy this latest issue:

'The pure and simple truth is rarely pure and never simple.'

1. NHS Centre for Reviews and Dissemination. A Systematic Review of Water Fluoridation. York: NHS Centre for Reviews and Dissemination, University of York; 2000 (see http://www.york.ac.uk/inst/crd/ fluorid.htm).

2. McDonagh MS, Whiting PF, Wilson PM, Sutton AJ, Chestnutt I, Cooper J, et al. Systematic review of water fluoridation. BMJ 2000; 321:855-859 (see http:// bmj.com/cgi/content/full/321/7265/855). 